\title{
Separation of Inorganic Anions on a Chemically Bonded 18-Crown-6 Ether Stationary Phase in Capillary Ion Chromatography
}

\author{
Toyohide TAKeuChI, ${ }^{\dagger}$ Kimi TokUnaga, and Lee Wah LiM \\ Department of Chemistry, Faculty of Engineering, Gifu University, 1-1 Yanagido, Gifu 501-1193, Japan
}

\begin{abstract}
Inorganic anions were separated on a chemically bonded 18-crown-6 ether (18C6E) stationary phase in capillary ion chromatography. In this study $18 \mathrm{C} 6 \mathrm{E}$ groups were chemically bonded on silica gel via reaction with 3-glycidyloxypropyltrimethoxysilane, followed by reaction with 2-aminomethyl-18C6E. Analyte anions were separated in the ion-exchange mode based on the fact that the eluent cation was trapped on the $18 \mathrm{C} 6 \mathrm{E}$ and it worked as the anion-exchange site. The eluent cation and eluent anion as well as the eluent concentration affected the retention of the analyte anions. Different selectivity was achieved by using an acetonitrile-rich eluent. The present stationary phase was applied for the determination of UV-absorbing anions contained in saliva samples.
\end{abstract}

(Received October 21, 2012; Accepted January 24, 2013; Published April 10, 2013)

\section{Introduction}

Various stationary phases have been developed in ion chromatography since it was initiated by Small et al. in $1975 .{ }^{1}$ Since ions are generally separated based on the difference in electrostatic interaction with the stationary phase, the stationary phases should possess charges that are inherently provided or dynamically acquired.

Crown ethers, typically 18 -crown-6 ether (18C6E), have been used to improve the resolution of cations in ion chromatography. ${ }^{2-5}$ For example, the addition of $18 \mathrm{C} 6 \mathrm{E}$ in the eluent apparently increases the retention of potassium ion to improve the resolution. This is because the association constant of complexation between $18 \mathrm{C} 6 \mathrm{E}$ and potassium ion is larger than that for the other cations. The unique ability of crown ethers to selectively complex alkali metal cations can be used as the basis for chromatographic separations of anions. ${ }^{6}$ It was reported that alkylated macrocycles such as $n$-tetradecyl-18C6E permanently coated onto a reversed-phase column formed positively charged anion-exchange sites when they combined with eluent cations, and that anion retention increased with increasing eluent strength and organic modifier content. ${ }^{6}$ We also reported that anions could be separated in the ion-exchange mode by using crown ether as the eluent additive and a reversed-phase stationary phase, where the eluent cation was trapped on the crown ether and worked as the anion-exchange site. ${ }^{7}$ Chiral crown ethers have also been successfully utilized as chiral selectors of chiral stationary phases for the liquid chromatographic separation of various enantiomers. ${ }^{8-10}$

Chemically bonded poly(oxyethylene) (POE) stationary phases could also separate anions in the ion-exchange mode. ${ }^{11,12}$ This is because the eluent cation was trapped by ion-dipole

† To whom correspondence should be addressed.

E-mail: take-t@gifu-u.ac.jp interaction with the oxygen atoms of multiple brush-type POE chains, and the eluent and analyte anions could compete for the trapped cation. Inorganic anions can therefore be separated on the POE-bonded phases in the ion-exchange mode, and nearly the same retention order as in common ion-exchange mode was observed.

In this study we prepared a chemically bonded 18C6E stationary phase and applied it for the separation of inorganic anions in capillary ion chromatography. The previous stationary phase was $\mathrm{C} 30$ dynamically modified with $18 \mathrm{C} 6 \mathrm{E},{ }^{7}$ while the present stationary phase was a chemically bonded $18 \mathrm{C} 6 \mathrm{E}$ stationary phase. Therefore, for the previous stationary phase $18 \mathrm{C} 6 \mathrm{E}$ should be included in the eluent, while it was not necessary to be included in the eluent for the present system. The eluent can be more simple for the present system, compared with the previous stationary phase. In addition, the $18 \mathrm{C} 6 \mathrm{E}$ reagents commercially available are so expensive that the capillary format was deemed suitable for the present project.

\section{Experimental}

Apparatus

The eluent was supplied by an L.TEX-8301 Micro Feeder (L. TEX Corp., Tokyo, Japan) equipped with an MS-GAN 050 gas-tight syringe $(0.5 \mathrm{~mL}$; Ito, Fuji, Japan) at a flow-rate of $8.0 \mu \mathrm{L} \mathrm{min}{ }^{-1}$. The inlet pressure was monitored by an L.TEX-8150 Pressure Sensor (L.TEX). Samples were loaded with a Model M435 microinjection valve with an injection volume of $0.15 \mu \mathrm{L}$ (Upchurch Scientific, Oak Harbor, WA). Separation columns were prepared in the laboratory by using fused-silica capillary with $0.53 \mathrm{~mm}$ i.d., according to the method previously reported. ${ }^{13}$ The separation columns were dipped in water to avoid the variation of the temperature. A UV-2070 UV detector (JASCO, Tokyo, Japan) was used as the detector and was operated at 210 or $254 \mathrm{~nm}$. A capillary flow cell $(75 \mu \mathrm{m}$; 

$\underset{\text { GPTMS }}{\left(-2 \mathrm{SiO}-\mathrm{H}+\mathrm{H}_{3} \mathrm{CO}\right)_{3} \mathrm{Si}_{-} \mathrm{C}_{3} \mathrm{H}_{6}-\mathrm{O}-\mathrm{CH}_{2}-\mathrm{CH}_{-} \mathrm{CH}_{2}}$
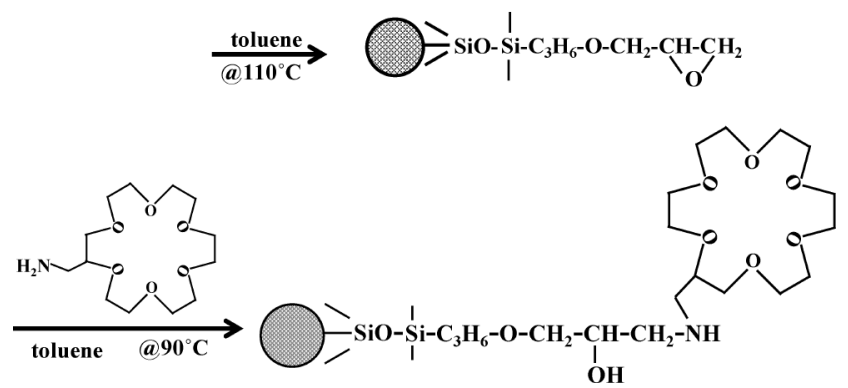

Fig. 1 Scheme for expected reactions.

JASCO) was equipped with the UV detector. All of the data were collected by a Chromatopac C-R4A data processor (Shimadzu, Kyoto, Japan). The elemental analysis of the prepared stationary phase was conducted by using a Micro Corder JM10 (J-Science Lab, Kyoto, Japan).

\section{Reagents and materials}

Reagents employed were of guaranteed reagent grade and were obtained from Wako Pure Chemical Industries (Osaka, Japan), unless otherwise noted. Supplies of 2-aminomethyl-18C6E were obtained from Sigma-Aldrich (St. Louis, MO) and 3glycidyloxypropyltrimethoxysilane (GPTMS) from Tokyo Chemical Industry (Tokyo, Japan). Purified water was produced in the laboratory by using an RFS432PA water distillation system (Advantec, Tokyo, Japan). Inorganic sample solutions and eluents for ion chromatography used in this work were prepared using the purified water. Toluene was dried over molecular sieves 3A (1/16" pellets). The average particle diameter of the silica gel employed was $5 \mu \mathrm{m}$ with mean pore diameter of $12 \mathrm{~nm}$ (Chemical Evaluation and Research Institute, Japan), and the silica gel was dried at $110^{\circ} \mathrm{C}$ for $2 \mathrm{~h}$ before use. Stainless-steel tubing with $100 \times 4.6 \mathrm{~mm}$ i.d. was used as the reaction vessel.

\section{Preparation of stationary phase}

A 0.2-g amount of the dried porous silica gel was placed in the reaction vessel, and $1.2 \mathrm{~mL}$ dry toluene and $0.2 \mathrm{~mL}$ of GPTMS were added to the vessel. The reaction was carried out at $110^{\circ} \mathrm{C}$ for $20 \mathrm{~h}$. The vessel was sometimes manually vibrated during the reaction. After the reaction, the reacted silica gel was washed with dry toluene, and the reaction vessel was filled with dry toluene including $60 \mathrm{mg}$ 2-aminomethyl-18C6E and kept at $90^{\circ} \mathrm{C}$ for $18 \mathrm{~h}$, followed by washing with methanol and water. Finally, 20\% (v/v) acetonitrile aqueous solution including sulfuric acid in $10 \mathrm{mM}$ was poured into the reaction vessel to open residual epoxy groups to form diol groups. The reaction was carried out at $40^{\circ} \mathrm{C}$ for $4 \mathrm{~h}$. The scheme of the expected reactions is shown in Fig. 1.

\section{Preparation of saliva sample}

A saliva sample was diluted 10 times with deionized water, and centrifuged at $3000 \mathrm{rpm}$ for $5 \mathrm{~min}$, followed by filtration with a $0.45-\mu \mathrm{m}$ membrane filter. The saliva sample was then stored in a refrigerator.

\section{Results and Discussion}

\section{Surface coverage of bonded phase}

The surface coverage of chemically bonded phases was estimated by elemental analysis. The coverage of $18 \mathrm{C} 6 \mathrm{E}$ was calculated to be $0.24 \mathrm{mmol} \mathrm{g}^{-1}$ from the nitrogen content, while the residual epoxy group was estimated to be $0.43 \mathrm{mmol} \mathrm{g}^{-1}$ from the carbon and nitrogen contents. In other words, GPTMS was introduced on the silica gel at a content of $0.67 \mathrm{mmol} \mathrm{g}^{-1}$ and $36 \%$ of the epoxy groups were reacted with 2-aminomethyl-18C6E.

Effect of eluent concentration on the retention of analyte anions The logarithm of the retention factor $(\log k)$ in the anion-exchange mode is given by the following equation: ${ }^{14}$

$$
\begin{aligned}
\log k= & -\left(Z_{\mathrm{A}-} / Z_{\mathrm{E}-}\right) \log \left[\mathrm{E}^{-}\right]_{\mathrm{m}}+\left(Z_{\mathrm{A}} / Z_{\mathrm{E}-}\right) \log \left[\mathrm{E}^{-}\right]_{\mathrm{s}}+ \\
& \left(1 / Z_{\mathrm{E}-}\right) \log K_{\mathrm{E}_{-}{ }^{\mathrm{A}-}}+\log V_{\mathrm{s}} / V_{\mathrm{m}}
\end{aligned}
$$

where $\left[\mathrm{E}^{-}\right]_{\mathrm{m}}$ and $\left[\mathrm{E}^{-}\right]_{\mathrm{s}}$ are the concentration of the eluent anion in the mobile phase and the stationary phase, $K_{\mathrm{E}_{-}^{-}}{ }^{\mathrm{A}-}$ is the selectivity (or equilibrium constant) of the analyte anion, $Z_{\mathrm{A}-}$ and $Z_{\mathrm{E}-}$ are the absolute values of the valency of the analyte anion and the eluent anion, and $V_{\mathrm{s}}$ and $V_{\mathrm{m}}$ are the volume of the stationary phase and the mobile phase, respectively. Since $\left[\mathrm{E}^{-}\right]_{\mathrm{s}}$ is estimated to be nearly equal to the anion-exchange capacity under usual operating conditions, $\left[\mathrm{E}^{-}\right]_{\mathrm{S}}$ is equal to the concentration of the eluent cation $\left(\mathrm{E}^{+}\right)$trapped by $18 \mathrm{C} 6 \mathrm{E}$ in the stationary phase multiplied by the valency of the eluent cation $\left(Z_{\mathrm{E}+}\right): Z_{\mathrm{E}+}\left[18 \mathrm{C} 6 \mathrm{E}-\mathrm{E}^{+}\right]_{\mathrm{s}}$. Furthermore, since the third and the fourth terms of Eq. (1) are commonly constant and $\left[\mathrm{E}^{-}\right]_{\mathrm{m}}$ is equal to $\left(Z_{\mathrm{E}+} / Z_{\mathrm{E}-}\right)\left[\mathrm{E}^{+}\right]_{\mathrm{m}}$, Eq. (1) is rewritten by Eq. (2):

$$
\log k=\left(Z_{\mathrm{A}-} / Z_{\mathrm{E}-}\right) \log \left(Z_{\mathrm{E}-}\left[18 \mathrm{C} 6 \mathrm{E}-\mathrm{E}^{+}\right]_{\mathrm{s}} /\left[\mathrm{E}^{+}\right]_{\mathrm{m}}\right)+\mathrm{C}
$$

Since the stability constant between $18 \mathrm{C} 6 \mathrm{E}$ and the eluent cation $\left(K_{18 \mathrm{C} 6 \mathrm{E}-\mathrm{E}+}\right)$ is equal to $\left[18 \mathrm{C} 6 \mathrm{E}-\mathrm{E}^{+}\right]_{\mathrm{s}} /\left\{[18 \mathrm{C} 6 \mathrm{E}]_{\mathrm{s}}\left[\mathrm{E}^{+}\right]_{\mathrm{m}}\right\}$, Eq. (2) is expressed by the following equation:

$$
\log k=\left(Z_{\mathrm{A}-} / Z_{\mathrm{E}-}\right) \log \left(Z_{\mathrm{E}-} K_{18 \mathrm{C} 6 \mathrm{E}-\mathrm{E}+}[18 \mathrm{C} 6 \mathrm{E}]_{\mathrm{s}}\right)+\mathrm{C}
$$

where $[18 \mathrm{C} 6 \mathrm{E}]_{\mathrm{s}}$ is the concentration of free (or unassociated) $18 \mathrm{C} 6 \mathrm{E}$ in the stationary phase. Equation (3) indicates that the retention of the analyte anion depends on the concentration of free $18 \mathrm{C} 6 \mathrm{E}$ in the stationary phase as well as on the stability constant between $18 \mathrm{C} 6 \mathrm{E}$ and the eluent cation. This means that when the eluent concentration increases, it can be expected that the concentration of free $18 \mathrm{C} 6 \mathrm{E}$ in the stationary phase decreases, which will lead to a decrease in the retention of analyte anions. Actually, when the concentration of the eluent increases, the eluting strength increases, whereas the ion-exchange site also increases. Both contributions are competing for the retention of analyte anions as seen in Eq. (2), and Eq. (3) indicates that the former contribution is dominant.

Figure 2 shows the effect of the eluent concentration on the retention of analyte anions, where $\mathrm{KCl}$ is used as the eluent and $\mathrm{IO}_{3}^{-}, \mathrm{BrO}_{3}^{-}, \mathrm{Br}^{-}, \mathrm{NO}_{2}^{-}, \mathrm{NO}_{3}^{-}, \mathrm{I}^{-}$and $\mathrm{SCN}^{-}$are injected. It can be seen that the analyte anions are well separated except for $\mathrm{Br}$ and $\mathrm{NO}_{2}^{-}$under the operating conditions in Fig. 2. As discussed above, the retention of the analyte anions actually decreases with increasing eluent concentration. In the present separation system the ion-exchange sites are eluent cations dynamically trapped on the crown ether. On the other hand, conventional anion-exchangers inherently possess a positive charge. The same separation system as the crown ether can be demonstrated 


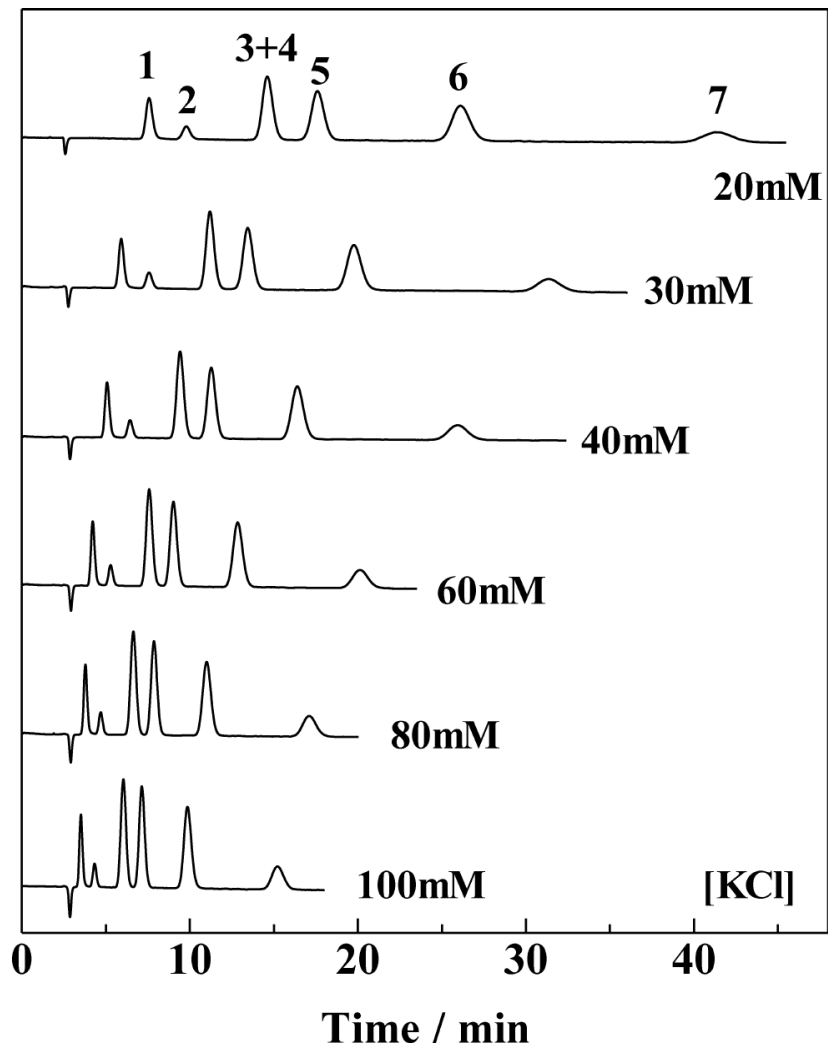

Fig. 2 Separation of inorganic anions at different $\mathrm{KCl}$ concentrations. Column: $18 \mathrm{C} 6 \mathrm{E}, 100 \times 0.53 \mathrm{~mm}$ i.d. Eluent: $\mathrm{KCl}$, concentrations as

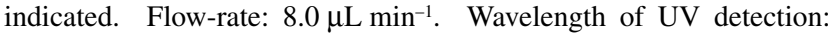
$210 \mathrm{~nm}$. Analyte: $0.2 \mathrm{mM}$ each $(0.15 \mu \mathrm{L}) ; 1=\mathrm{IO}_{3}^{-}, 2=\mathrm{BrO}_{3}^{-}, 3=\mathrm{Br}^{-}$, $4=\mathrm{NO}_{2}^{-}, 5=\mathrm{NO}_{3}^{-}, 6=\mathrm{I}^{-}, 7=\mathrm{SCN}^{-}$.

by using chemically bonded polyoxyethylene as the stationary phase. ${ }^{11}$ The polyoxyethylene stationary phase also traps the eluent cation and it works as the anion-exchange site. The polyoxyethylene stationary phase cannot separate nitrite and bromide. Nitrite and bromide cannot be separated on the stationary phases the anion-exchange site of which is dynamically trapped eluent cation.

\section{Effect of eluent cation on the retention of analyte anions}

Since the concentration of the $18 \mathrm{C} 6 \mathrm{E}$ functional group associated with the eluent cation increases with increasing stability constant, it is expected from Eq. (3) that the retention of analyte anions is larger when the eluent cation with a larger stability constant is employed. Figure 3 demonstrates the separation of inorganic anions using various chlorides as the eluent, where the chloride concentration in the eluent is kept at $100 \mathrm{mM}$. It can be seen that $\mathrm{KCl}$ gives the largest retention of the analyte anions, followed by $\mathrm{RbCl}$. The stability constants for various metal ions are shown in Table $1 .{ }^{15,16}$ It was found that the stability constant of $\mathrm{K}^{+}$is the largest, followed by $\mathrm{Rb}^{+}$, $\mathrm{NH}_{4}^{+}, \mathrm{Cs}^{+}, \mathrm{Na}^{+}$and $\mathrm{Li}^{+}$for monovalent cations in this order. The eluent cation with a larger stability constant had a tendency to give larger retention of the analyte anions, as shown in Fig. 3 and Table 1.

The retention time of chloride as the water dip represents the amount of the trapped eluent cation. It is expected that the longer the retention time of water dip, the larger the amount of the trapped eluent cation. The elution time of the water dip depended on the eluent cation, as seen in Fig. 3. It is considered

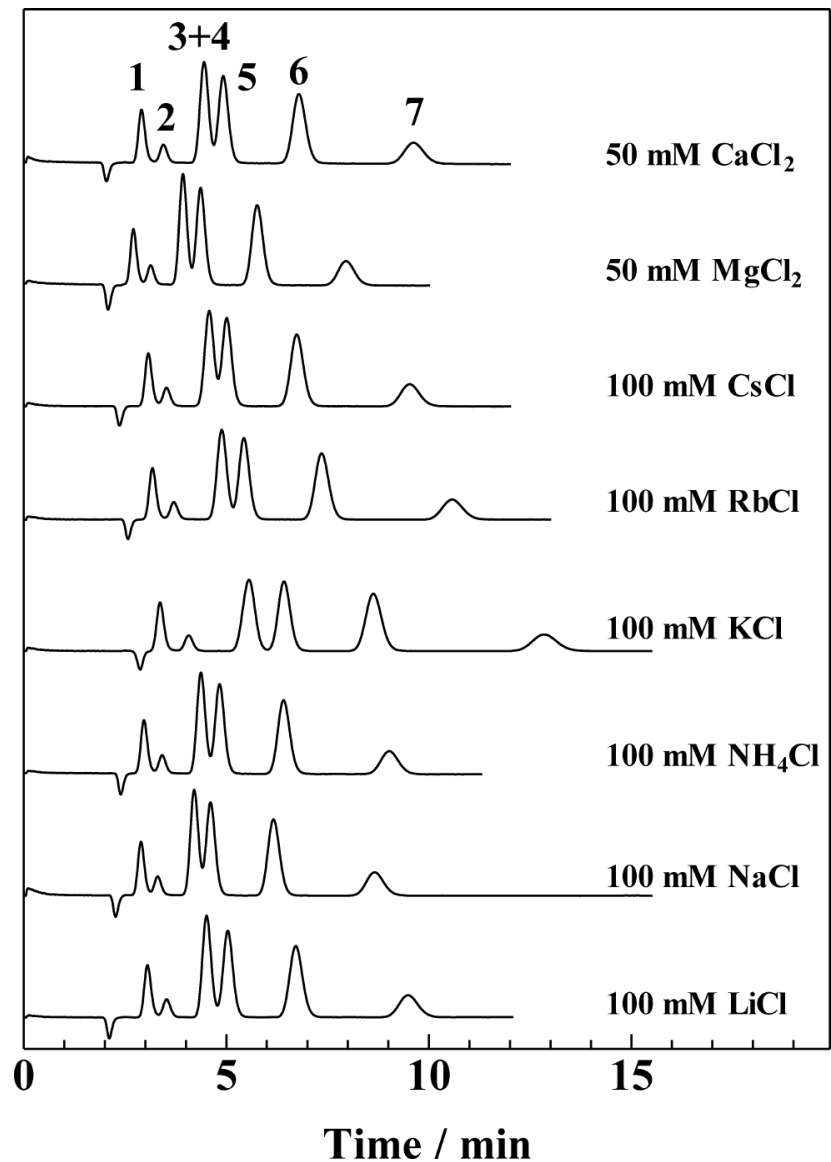

Fig. 3 Effect of the eluent cation on the retention of analyte anions. Eluent: as indicated. Other operating conditions as in Fig. 2.

Table 1 Stability constant between 18C6E and metal cations

\begin{tabular}{cccc}
\hline Ligand & Cation & $\log K$ & Ref. \\
\hline \multirow{2}{*}{$18 \mathrm{C} 6 \mathrm{E}$} & $\mathrm{Li}^{+}$ & $\sim 0$ & 15 \\
& $\mathrm{Na}^{+}$ & $0.80 \pm 0.10$ & 16 \\
& $\mathrm{~K}^{+}$ & $2.03 \pm 0.10$ & 16 \\
& $\mathrm{Rb}^{+}$ & $1.56 \pm 0.02$ & 16 \\
& $\mathrm{Cs}^{+}$ & $0.99 \pm 0.07$ & 16 \\
& $\mathrm{NH}_{4}{ }^{+}$ & $1.23 \pm 0.06$ & 16 \\
& $\mathrm{Mg}_{2}{ }^{+}$ & - & - \\
& $\mathrm{Ca}^{+}$ & $<0.5$ & 16 \\
\hline
\end{tabular}

that the elution time of the water dip corresponds to the retention time of chloride ion, because the sample solution does not contain chloride, corresponding to the injection of minus $100 \mathrm{mM}$ chloride under the conditions in Fig. 3. Table 2 shows the elution time of the water dip when aqueous solutions of various chlorides were used as the eluent. The retention time of $\mathrm{SCN}^{-}$is also shown in the table. The dead volume of the separation system was subtracted from the actual observed elution time, and the corrected values are shown in the table. Table 2 shows that the correlation between the elution time of water dip and the stability constant is high. As for monovalent eluent cations, a high correlation $(r=0.716)$ is observed between the elution time of water dip and the logarithm of the stability constant $(\log K)$, as depicted in Fig. 4. On the other hand, there were some exceptions to the correlation between the retention time of $\mathrm{SCN}^{-}$and the stability constant, as shown in 
Table 2 Elution time of water dip depending on the type of chloride used as the eluent

\begin{tabular}{lccc}
\hline Eluent(mM) & $\begin{array}{c}\text { Elution time of } \\
\text { water dip/min }\end{array}$ & $\begin{array}{c}\text { Retention time of } \\
\text { SCN }^{-}\end{array}$ & $\log K^{\mathrm{a}}$ \\
\hline $\mathrm{KCl}(100)$ & 2.70 & 12.67 & $2.03 \pm 0.10$ \\
$\mathrm{RbCl}(100)$ & 2.40 & 10.36 & $1.56 \pm 0.02$ \\
$\mathrm{NH}_{4} \mathrm{Cl}(100)$ & 2.22 & 8.84 & $1.23 \pm 0.06$ \\
$\mathrm{CsCl}(100)$ & 2.19 & 9.35 & $0.99 \pm 0.07$ \\
$\mathrm{NaCl}(100)$ & 2.09 & 8.46 & $0.80 \pm 0.10$ \\
$\mathrm{LiCl}(100)$ & 1.94 & 9.31 & $\sim 0$ \\
$\mathrm{MgCl}_{2}(50)$ & 1.91 & 7.75 & - \\
$\mathrm{CaCl}_{2}(50)$ & 1.87 & 9.45 & $<0.5$ \\
\hline
\end{tabular}

a. $K$ : Stability constant between each eluent cation and $18 \mathrm{C} 6 \mathrm{E}$ in water.

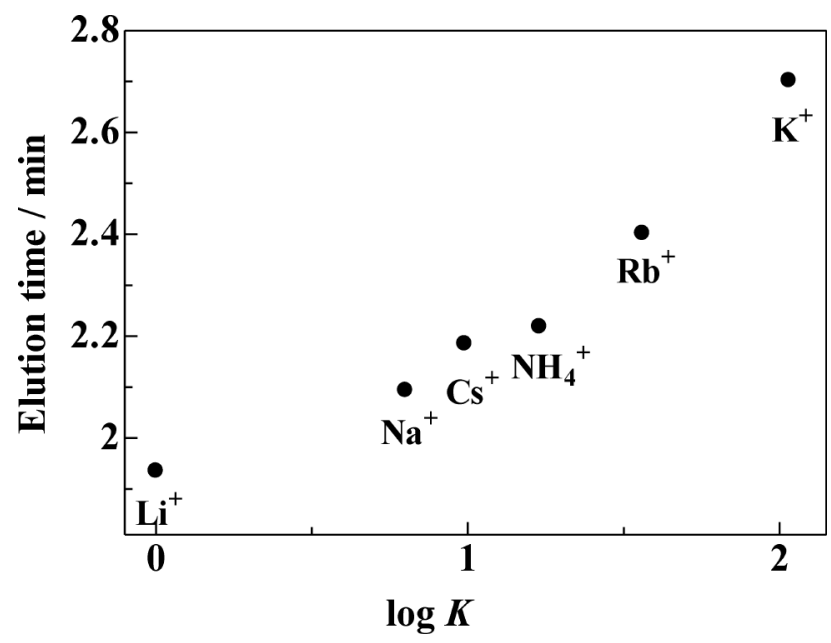

Fig. 4 Correlation between the elution time of water dip and the logarithm of the stability constant. Operating conditions as in Fig. 3.

Table 2, although the reason for this is not elucidated, yet.

In addition, it was difficult to determine the elution time of non-retained analytes for the present separation system. For example, the elution times of methanol and uracil were 2.24 and $2.29 \mathrm{~min}$, respectively, when $100 \mathrm{mM} \mathrm{KCl}$ was used as the eluent. These values are larger than the elution times of the water dip shown in Table 2 except for $\mathrm{KCl}$ and $\mathrm{RbCl}$.

Effect of eluent anion on the retention of analyte anions

The effect of the eluent anion on the retention of analyte anions was also examined. Figure 5 depicts the separation of inorganic anions on the 18C6E stationary phase using four different potassium solutions as the eluent. It can be seen that $100 \mathrm{mM} \mathrm{KH} \mathrm{KO}_{4}$ gives the largest retention of the analyte anions, whereas $100 \mathrm{mM} \mathrm{KClO}_{4}$ gives the smallest retention. It

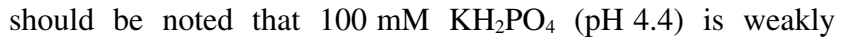
acidic, whereas the others are neutral solutions. It is therefore speculated that the secondary amino group of the $18 \mathrm{C} 6 \mathrm{E}$ stationary phase can be protonated, and it is expected that the retention of the analyte anions on the protonated amino group as well as on the $\mathrm{K}^{+}$-trapped $\mathrm{C} 186 \mathrm{E}$ is a reason for larger retention of the analyte anions observed in Fig. 5.

Separation of anions under acetonitrile-rich eluent condition

The selectivity of analyte anions can be varied by adding an organic solvent in the eluent. Figure 6 shows the separation of

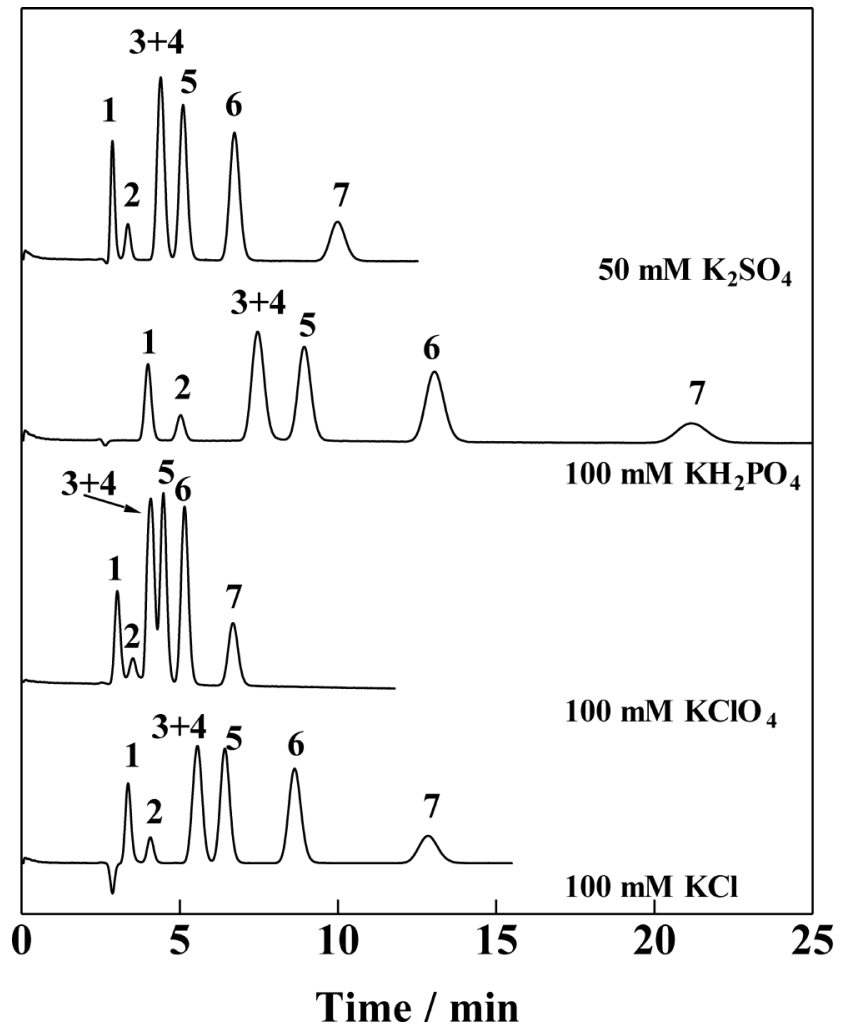

Fig. 5 Separation of inorganic anions using different potassium solutions as the eluent. Eluent: as indicated. Other operating conditions as in Fig. 2.

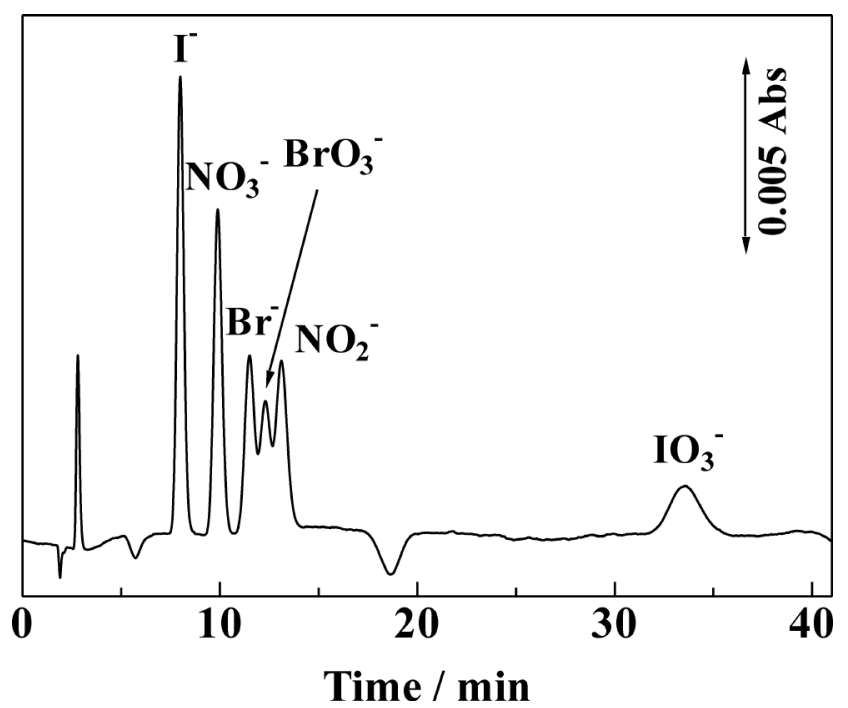

Fig. 6 Separation of anions using an acetonitrile-rich eluent. Eluent: $5 \mathrm{mM}$ ammonium acetate in $85 \%$ acetonitrile. Other operating conditions as in Fig. 2.

seven UV-absorbing anions using $5 \mathrm{mM}$ ammonium acetate in $85 \%$ acetonitrile as the eluent. It can be seen that the elution order of the analyte anions in Fig. 6 is quite different from that observed in Fig. 2. The difference in the selectivity observed in Fig. 6 is due to dehydration of analyte anions under acetonitrile-rich eluent. Bromide and nitrite can be separated under the conditions in Fig. 6 . In addition, under the conditions 


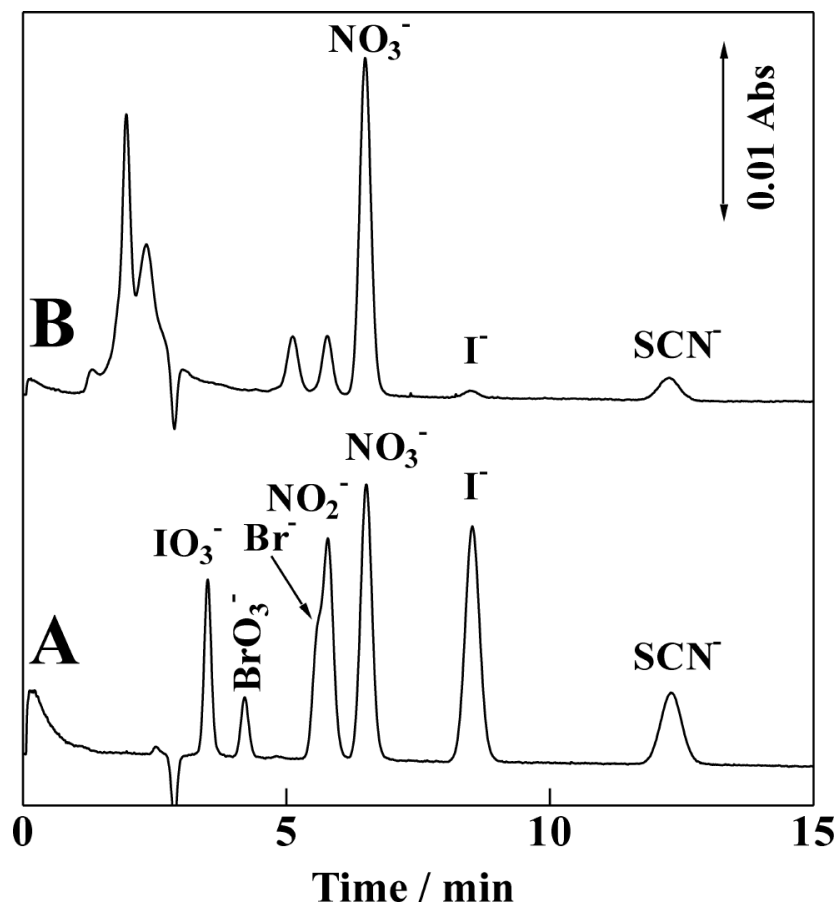

Fig. 7 Separation of authentic mixture of seven UV-absorbing anions and UV-absorbing species contained in a saliva sample. Eluent: $100 \mathrm{mM} \mathrm{KCl}$. Analyte: $0.2 \mathrm{mM}$ each $(0.15 \mu \mathrm{L}) ; 1=\mathrm{IO}_{3}^{-}, 2=\mathrm{BrO}_{3}^{-}$, $3=\mathrm{Br}^{-}, 4=\mathrm{NO}_{2}^{-}, 5=\mathrm{NO}_{3}^{-}, 6=\mathrm{I}^{-}, 7=\mathrm{SCN}^{-}(\mathrm{A})$ and 10-time diluted saliva (B). Other operating conditions as in Fig. 2.

in Fig. 6, thiocyanate eluted earlier than iodide. However, they eluted very close to each other, and they could not be separated.

\section{Application for the determination of anions in saliva}

The present system was applied for the determination of UV-absorbing anions contained in a saliva sample. Figure 7 illustrates the separation of inorganic UV-absorbing anions contained in a saliva sample together with an authentic mixture of seven anions using a $10-\mathrm{cm}$ column, where bromide eluted close to nitrite and these two anions could not be resolved under the present operating condition. The concentration of nitrate, iodide and thiocyanate was determined to be $153,7.3$ and $36 \mathrm{mg} \mathrm{L}^{-1}$, respectively.

\section{Conclusions}

This study demonstrated that 18C6E-bonded stationary phases trapped eluent cations to provide the anion-exchange sites, allowing the separation of inorganic anions. The eluent cation as well as the eluent anions remarkably affected the retention of the analyte anions. The retention time of the analyte anions can be controlled by careful selection of an additive in the eluent.

\section{References}

1. H. Small, T. S. Stevens, and W. C. Bauman, Anal. Chem., 1975, 47, 1801.

2. P. R. Haddad and P. E. Jackson, "Ion Chromatography: Principles and Applications (J. Chromatogr. Library Vol. 46)", 1990, Elsevier, Amsterdam, London, New York, Tokyo, 233.

3. J. D. Lamb and R. G. Smith, J. Chromatogr., A, 1991, 546, 73.

4. M. W. Läubi and B. Campus, J. Chromatogr., A, 1995, 706, 103 .

5. K. Ohta, K. Kusumoto, Y. Takao, A. Towata, S. Kawakami, M. Ohashi, and T. Takeuchi, Chromatographia, 2003, 58 , 171.

6. J. D. Lamb, R. G. Smith, and J. Jagodzinski, J. Chromatogr., A, 1993, 640, 33.

7. T. Takeuchi and L. W. Lim, Anal. Sci., 2011, 27, 1019.

8. H. S. Cho, H. J. Choi, and M. H. Hyun, J. Chromatogr., A, 2009, 1216, 7446 .

9. Y. Machida, H. Nishi, K. Nakamura, H. Nakai, and T. Sato, J. Chromatogr., A, 1998, 805, 82.

10. M. H. Hyun, J. Sep. Sci., 2006, 29, 750.

11. T. Takeuchi and L.W. Lim, Anal. Sci., 2010, 26, 937.

12. L.W. Lim, L. Rong, and T. Takeuchi, Anal. Sci., 2012, 28, 205.

13. T. Takeuchi and D. Ishii, J. Chromatogr., 1981, 213, 25.

14. J. S. Fritz and D. T. Gjerde, "Ion Chromatography", 3rd, completely revised and enlarged ed., Wiley-VCH, Weinheim, 2000, 88.

15. A. J. Smetana and A. I. Popov, J. Solution Chem., 1980, 9, 183.

16. R. M. Izatt, R. E. Terry, B. L. Haymore, L. D. Hansen, N. K. Dalley, A. G. Avondet, and J. J. Christensen, J. Am. Chem. Soc., 1976, 98, 7620. 